\title{
Avian Lampbrush Chromosomes: a Powerful Tool for Exploration of Genome Expression
}

\author{
E. Gaginskaya T. Kulikova A. Krasikova \\ Saint-Petersburg State University, Saint-Petersburg, Russia
}

\author{
Key Words \\ Chicken genome $\cdot$ Chromosome organization $\cdot$ Lampbrush \\ chromosomes - Non-coding RNA - Oocyte nucleus • \\ Oogenesis $\cdot$ Transcription
}

\begin{abstract}
Lampbrush chromosomes (LBCs) are highly extended bivalents that function in the growing oocytes of many animals. Due to their distinctive chromomere-loop organization and intense transcriptional activity of lateral loops the LBCs, mainly amphibian ones, have served as a powerful system for exploring the general principles of chromosome organization and function. The exploitation of avian LBCs has considerably broadened the opportunities for comparative genome research and for cytogenetic analysis of domestic species. In this review we highlight the advantages of avian LBCs for research in different areas including integration of genome organization studies with studies on gene activity in vivo, analysis of co-transcriptional events occurring on nascent transcripts and investigation of chromosome-associated intranuclear domains. Recent findings concerning the organization of transcriptionally active and silent chromatin together with involvement of cohesin and condensin complexes into maintenance of structural integrity of LBCs are presented. The biological significance of the LBC phenomenon is discussed. The intensive transcription on LBCs shows
\end{abstract}

some specific features: very long transcription units, deregulated termination, and transcription of non-coding satellite repeats. Here, based on the modern view on a role of RNA interference machinery in regulation of genome expression, we suggest a mechanism of initiation of satellite DNA transcription and offer a novel interpretation of the 'classical' hypothesis that sought to explain the significance of widespread transcription during oocyte growth.

Copyright $\odot 2009$ S. Karger AG, Basel

The investigation of genome structure and function has been greatly helped by studies of model systems such as polytene and lampbrush chromosomes that facilitate exploration of gene activity in vivo. In this respect, giant lampbrush chromosomes (LBCs) deserve special attention. They represent a special form of meiotic chromosomes, which is assumed during oocyte growth in most animals other than mammals [Callan, 1986; Macgregor, 1987, 2002] except for some monotremes [Lintern-Moore et al., 1976].

LBCs were first observed in 1882 by W. Flemming in amphibian oocytes and investigated in detail by J. Rückert in shark oocytes in 1892. Actually, we owe the name 'lampbrush chromosome' to J. Rückert, who compared them with bristled brushes for cleaning oil lamps. The history of discovery and early studies of amphibian LBCs

\section{KARGER}

Fax +4161306 1234

E-Mail karger@karger.ch

www.karger.com
(C) 2009 S. Karger AG, Basel

1424-8581/09/1244-0251\$26.00/0

Accessible online at:

www.karger.com/cgr
Alla Krasikova

Saint-Petersburg State University

Oranienbaumskoie sch. 2, Stary Peterhof

Saint-Petersburg, 198504 (Russia)

Tel. +7 812450 7311, Fax +7 812450 7310, E-Mail spbchromas@gmail.com 
Fig. 1. Avian lampbrush chromosomes (LBCs): general view and scheme of organization. a Chaffinch lampbrush bivalent 2 stained with Coomassie blue R250. Two half-bivalents with a characteristic chromomere-loop organization are joined at chiasmata (arrows). Terminal giant loops (TGLs) and centromere protein bodies (PBs) associated with avian LBCs are indicated. b Quail lampbrush bivalent 3. Immunostaining with antibodies against the elongating form of RNA polymerase II. Lateral loops representing sites of active transcription are brightly stained. Scale bars $=10 \mu \mathrm{m}$. c Schematic drawing of a segment of lampbrush half-bivalent and the enlarged image demonstrating involvement of cohesin (red) and condensin (green) complexes into structural maintenance of the LBC axes. Sister chromatids (arrowheads), 'double loop' bridge (DLB) and transcription units (arrows) are indicated.
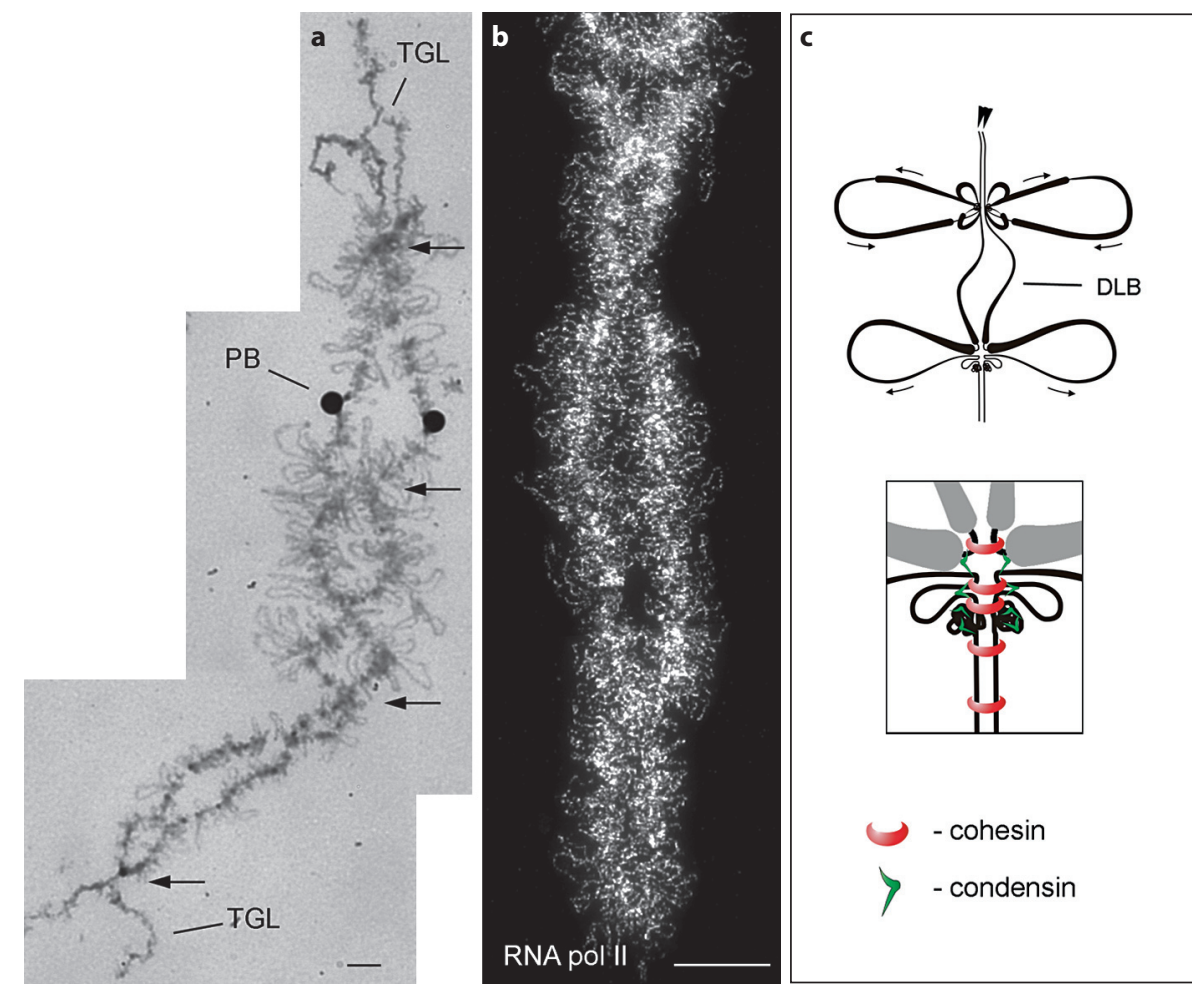

are perfectly described in the monograph by Callan [1986]. Holl [1890] was the first who described avian LBCs during examination of chicken oocytes. Later the morphology of chromosomes of that type was investigated in pre-vitellogenic oocytes in other avian species namely Columbiformes, Charadriformes, Strigiformes, Anseriformes, Galliformes and Passeriformes by routine histological technique [Loyez, 1906; van Durme, 1914; Brambell, 1926; Greenfield, 1966; Gaginskaya and Gruzova, 1969; Gaginskaya, 1972a, b; Wylie, 1972; Guraya, 1976; Gaginskaya and Chin, 1980].

The real era of 'lampbrushology' began 70 years ago, when Duryee [1937] offered the method of LBCs microdissection from the amphibian germinal vesicle (GV). The method of microsurgical isolation and spreading of the nuclear content on the microscope slide was then improved and modified by Gall [1954, 1966] and Callan [Callan and Lloyd, 1960]. Introduction of the technique was possible due to enormous GV size that enables performance of various microsurgery manipulations. Furthermore, telomere regions of LBCs are not attached to the nuclear envelope so that intact chromosomes can be easily isolated [Macgregor and Varley, 1988]. It was demonstrated too that intact GV manually isolated under mineral oil maintains its transcriptional activity and can be efficiently used for analysis of dynamics of fusion proteins within intranuclear structures [Lund and Paine, 1990; Patel et al., 2008].

Chromosomes in the lampbrush form occur at the diplotene stage of meiotic prophase I when the oocyte enters the period of cytoplasmic growth (pre-vitellogenesis). They are highly extended bivalents, in which homologous chromosomes are united at chiasmata (fig. 1a). Each half-bivalent has characteristic chromomere-loop morphology and is represented by an array of discrete globules of compact chromatin (chromomeres) with pairs of lateral loops expanded outward [Macgregor, 1984; Callan, 1986; Gaginskaya, 1989; Morgan, 2002; Gall et al., 2004]. Lateral loops correspond to transcriptionally active regions of chromosomes, in which sister chromatids are fully separated (fig. 1b). Transcription on lateral loops is very intensive, so that nascent transcripts complexed with proteins, produce a bulk of RNP matrix, which can be easily visualized in a light microscope. Lateral loops of normal [according to Callan, 1986], or simple [according to Morgan, 2002], morphology contain one or several transcription units. RNP matrix becomes thicker towards the ends of transcription units due to increase in 
the length of transcripts and the quantity of RNP (fig. 1c). In the lateral loops, neighboring transcription units can be orientated in the same or opposite directions. From the very early works on amphibian LBCs, these amazing objects have attracted the attention of investigators due to giant size, transcriptional activity, the distinctive chromomere-loop organization, and also because of their aesthetic beauty. Morgan [2002] summarizes recent data on the organization and functioning of chromosomes during the lampbrush phase and molecular composition of specialized nuclear structures - both associated with LBCs and extrachromosomal.

After the method of LBCs isolation was adapted to avian oocytes [Koecke and Müller, 1965; Kropotova and Gaginskaya, 1984; Hutchison, 1987; Solovei et al., 1992], a new promising phase in the lampbrushology began. For many reasons, exploration into avian LBCs proved to be highly rewarding. Birds belong to warm-blood amniotes. Moreover, they possess a special intermediate type of oogenesis between the so-called solitary and nutrimental types [Koschelt and Heider, 1902; Gaginskaya, 1975]. As with amphibian oocytes, the avian GV has a full set of LBCs, which are typical diplotene bivalents revealing all characteristic features of this chromosome type with well defined chromomeres and long lateral loops (fig. 1a, b). At the same time, in the ovary of adult birds, in contrast to amphibians, all oocytes are characterized by lack of ribosomal DNA amplification and by inactivated nucleolus organizers (NORs). Therefore, avian GV contain neither multiple extra-chromosomal nucleoli nor even chromosomal ones [Gaginskaya and Gruzova, 1969, 1975]. The avian genome is small (C value varies from 1.2 to 2.0 pg) because of a relatively low content of repeated DNA [Organ et al., 2007]. Being an important model organism for embryological and biomedical research and having agricultural significance, birds are now a subject of intensive genome research. The annotated chicken (Gallus gallus domesticus) genome databases are available online due to the progress of the Chicken Genome Project [ICGSC, 2004]. Moreover, projects on sequencing of turkey (Meleagris gallopavo), California condor (Gymnogyps californianus) and zebra finch (Taeniopygia guttata) genomes have been initiated recently.

Avian LBCs are thus highly suitable for exploration into general questions of eukaryotic genome expression and its regulation. Here we will discuss the advantages of the LBC and GV model for the investigations of chromosome structure and genome function with a special focus on avian LBCs.

Avian Lampbrush Chromosomes

\section{Chromomere Organization during the Lampbrush Phase}

LBCs provide a well-characterized and original system for precise investigation of chromatin epigenetic modifications, as well as structure and organization of meiotic bivalents [Macgregor et al., 1997]. Mechanisms which establish and maintain structural integrity of chromosomes of this type during the very long period of oocyte growth are still not fully understood. Obviously, chromomere-loop configuration of LBCs is sustained by a high level of transcriptional activity on the one hand and by a group of chromosomal structural proteins on the other hand. However, DNA topoisomerase II, which is known to participate in the condensation of mitotic chromatin, is not a component of amphibian [Fischer et al., 1993] or avian [Krasikova et al., 2004] LBCs.

The main candidates for the role of longitudinal and transverse molecular clips in LBC axes are proteins of the structural maintenance of chromosomes (SMC) group, involved in formation of cohesin and condensin complexes [Hagstrom and Meyer, 2003; Marko, 2008]. As to cohesins, two subunits of the SMC group and two additional proteins, in cooperation sufficient to form a cohesin complex, were found on the axes of avian LBCs [Krasikova et al., 2005]. It is important that sites of interactions of cohesins with LBC axes are distributed nonrandomly possibly reflecting identical epigenetic modifications of chromatin in half-bivalents that correlate with the size of lateral loops [Krasikova et al., 2005].

Earlier electron microscopy (EM) studies of avian LBCs spread by the Miller technique have provided strong evidence that within the chromomere chromatin is packed in the form of rosettes with pairs of loops symmetrically extended outward (fig. 1c). Ring-shaped cohesin apparently holds sister chromatids at the bases of sister lateral loops within the chromomere core as well as in the interchromomeric regions (fig. 1c). Indeed, the diameter of the cohesin ring ( $\sim 35 \mathrm{~nm})$ is large enough to embrace two $10-\mathrm{nm}$ fibers of chromatin [Hagstrom and Meyer, 2003]. Consistent with this explanation, in the regions of chromosome axes between the neighboring chromomeres only a single $20-\mathrm{nm}$ chromatin fiber could be visualized by EM [for references see Callan, 1986].

In each chromomere, organization of the chromatin of a single chromatid into a set of individual loops and maintenance of the untranscribed part of DNA in a condensed state seem to be carried out by condensin complexes responsible for the formation of intrachromatid cross-links (fig. 1c). In fact, condensin component XCAP-

Cytogenet Genome Res 2009;124:251-267 
D2 was found to be enriched in lampbrush chromomeres in Xenopus GVs [Beenders et al., 2003]. At the same time a stable protein scaffold was not observed in the LBC axes; instead interactions of certain chromosomal factors with lampbrush chromatin were demonstrated to be dynamic [Patel et al., 2008].

In accordance with the offered scheme of chromomere organization (fig. 1c), occurrence of the so-called 'double-axes' at consistent locations of LBCs could be explained by the lack of cohesin rings within the region, while appearance of 'double-loop bridges' (fig. 1c) could be explained in turn by the lack of condensin complexes. Both double-axes and double-loop bridges exist in the intact oocyte and are not a result of chromosome manual isolation [Callan and Lloyd, 1960; Macgregor and Klosterman, 1979]. For example, in chicken oocytes, the lampbrush bivalents 1, 2, 3 and ZW have stable axes, which are usually not interrupted by double-loop bridges. Whereas, from one to three double-loop bridges always appear in the middle of LBC 4 [Chelysheva et al., 1990; Galkina et al., 2006], which apparently has a lesser amount of condensins. The results of LBC studies with regard to their structural organization therefore support the recently presented 'SMC-crosslinked-chromatin-network' model for chromosome condensation [Marko, 2008].

\section{Epigenetic Modifications of Lampbrush Chromatin}

Overall epigenetic status of lampbrush chromatin has been intensively studied on the model of amphibian LBCs. Chromosomes of this type lack linker histone H1 [Hock et al., 1993], whereas in the lateral loops and chromomeres, histone $\mathrm{H} 4$ is predominantly hyperacetylated [Sommerville et al., 1993]. These characteristics of LBC chromatin reflect their high transcriptional activity. Experiments on modifications of histone tails by methylases and acetylases showed that simple lateral loops could reversibly retract and extend as a result of changes in transcriptional activity [Sommerville et al., 1993; Ryan et al., 1999; Smillie et al., 2004; Stewart et al., 2006]. In addition, chromatin-associated and non-chromatin-associated histones were found to be continually exchanged in transcriptionally active regions of LBCs [Stewart et al., 2006].

In general, chromatin of avian LBCs possesses the same characteristics as chromatin of amphibian LBCs. Indeed, the simultaneous demonstration of the elongating form of RNA polymerase II and histones confirms that on transcription units relatively long regions, tightly occupied by RNA polymerase complexes, alternate with very short regions packed with nucleosomes containing hyperacetylated histone $\mathrm{H} 4$ (fig. 2a, b). At the same time, chromatin in the chromomere has a more complex pattern of histone modifications. Within the chromomere, epigenetic markers of condensed and inactive chromatin have been revealed along with epigenetic markers of the 'open chromatin'. Recent observations suggest that the majority of chromomeres in chicken LBCs are enriched with histone H3K9-dimethyl and H3K27-dimethyl modifications typical of facultative heterochromatin. Chromomeres also contain a marker of transcriptionally active chromatin (hyperacetylated histone $\mathrm{H} 4$ ), both in amphibian [Sommerville et al., 1993] and in avian LBCs (fig. 2a). This could be explained by the presence of numerous miniature lateral loops with a contour length of about $1 \mu \mathrm{m}$ that extend from the chromomere core [Kropotova and Gaginskaya, 1984].

Available data on accurate localization of single copy and repetitive sequences on avian LBCs permits analysis of their epigenetic modifications during oogenesis. One of the instances is the chromatin containing repetitive sequences in chicken ZW lampbrush bivalents. Detailed descriptions of the morphology of sex chromosomes in the lampbrush form from 6 species of birds can be found in the article by Solovei et al. [1993]. In brief, in avian oocytes, $\mathrm{Z}$ and $\mathrm{W}$ sex chromosomes form an asymmetrical bivalent with a single chiasma. In the chicken $\mathrm{ZW}$ bivalent, the $\mathrm{Z}$ chromosome exhibits normal lampbrush morphology, whereas the $\mathrm{W}$ chromosome is predominantly condensed and packed into several dense chromomeres with only a few lateral loops [Solovei et al., 1993; Mizuno and Macgregor, 1998]. Repetitive sequences constitute from 70 to $90 \%$ of DNA in the chicken W chromosome [Saitoh et al., 1991; Schmid et al., 2005].

Recent data on the analysis of the histone modifications demonstrate that chromatin of $\mathrm{W}$ chromomeres is a typical silent chromatin: it lacks acetylated histone $\mathrm{H} 4$ and is enriched with $\mathrm{H} 3 \mathrm{~K} 9$-dimethyl and H3K27-dimethyl. In addition, DNA of W chromomeres was found to be highly methylated in comparison with the majority of chromomeres in other LBCs (our unpublished observations). High concentrations of heterochromatin protein 1 (HP1 $\beta$ ) within all W chromomeres (fig. $2 \mathrm{c}, \mathrm{d}$ ) together with the above described epigenetic modifications results in the condensation of $\mathrm{W}$ chromosomes throughout oogenesis.

There are other repetitive sequences forming constitutive heterochromatin blocks in the interphase nuclei that change their epigenetic status during the lampbrush 

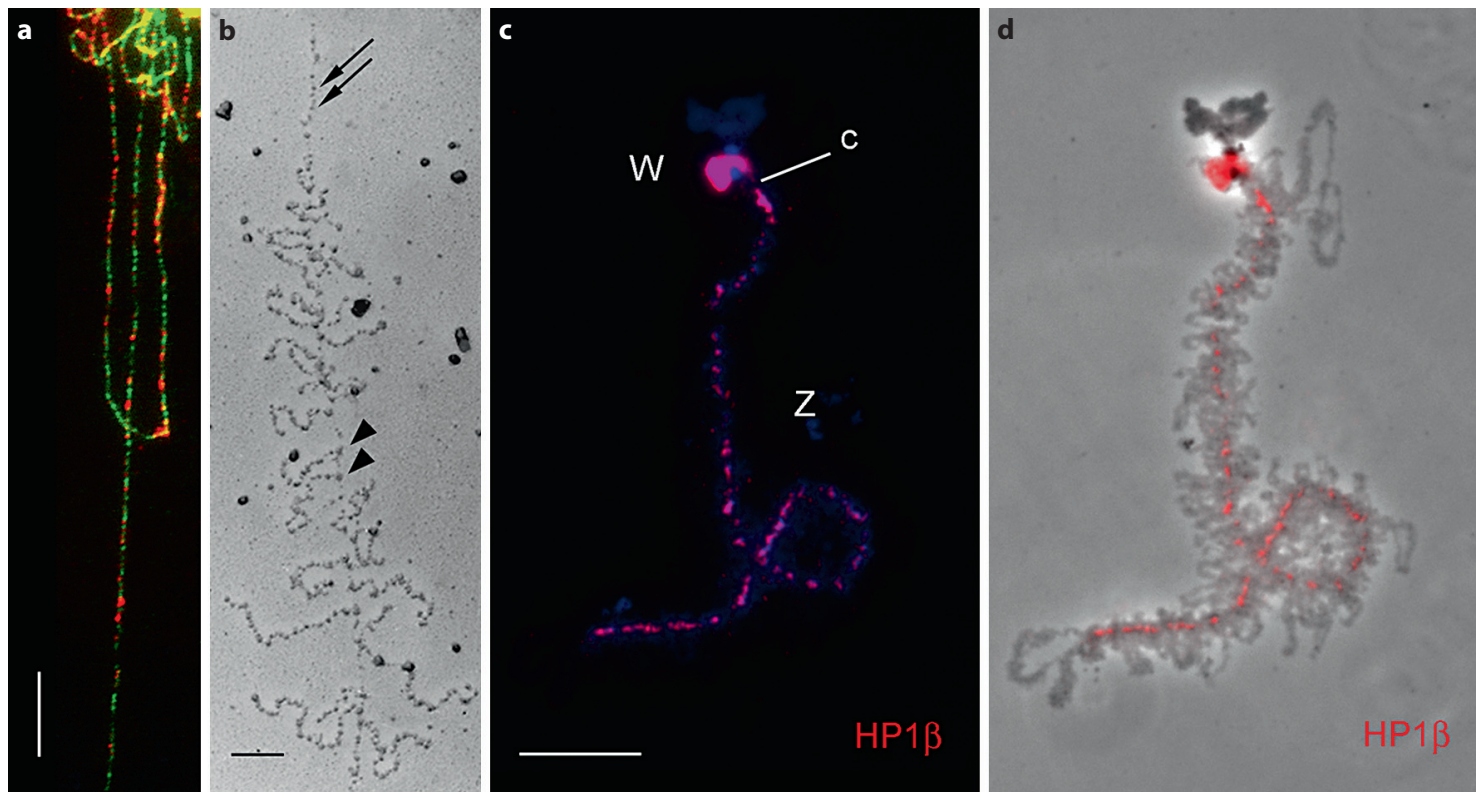

Fig. 2. Epigenetic characteristics of transcriptionally active and inactive chromatin of avian lampbrush chromosomes. a Distribution of RNA polymerase II complexes and nucleosomes on the axes of normal lateral loops. Double immunostaining with antibodies against elongating form of RNA polymerase II (green) and hyperacetylated histone H4 (H4Ac5) (red). Scale bar $=10 \mu \mathrm{m}$. b Chromatin of normal lateral loop spread by the Miller technique. Character of RNA polymerases and nucleosomes distribu- tion corresponds to that illustrated on panel a. Arrowheads indicate RNA polymerase complexes, arrows - nucleosomes. Scale bar $=0.2 \mu \mathrm{m}$. c, d Chicken ZW lampbrush bivalent. Immunostaining with antibody against heterochromatin protein $1 \beta$ (HP1 $\beta)(\mathrm{red})(\mathbf{c})$, and corresponding phase contrast image merged with fluorescent image (d). Chromomeres of $\mathrm{W}$ chromosome are brightly stained. Scale bar $=10 \mu \mathrm{m}$. phase. For example, chromatin of the C-positive block on the long arm of the Z-chromosome is known to be occupied by Z-macrosatellite repeats [Hori et al., 1996]. Unexpectedly, in the lampbrush phase, this region is not enriched with certain markers of heterochromatin such as protein HP1 $\beta$. Instead, it is remarkably decondensed and contains prolonged regions of chromatin forming lateral loops, which are occupied by hyperacetylated histone $\mathrm{H} 4$. Loop formation in this region could be explained by the intensive transcription of $\mathrm{Z}$ macrosatellites during the lampbrush stage [Hori et al., 1996]. Obviously, such changes lead to differential epigenetic characteristics of sex chromosomes during avian oogenesis.

\section{Avian Lampbrush Chromosomes as a Tool for High Resolution Cytogenetic Analysis}

Lateral loops representing the sites of the most active transcription as well as chromomeres representing nontranscribing chromatin have constant positions along the chromosome axis in different female individuals or oocytes [Callan, 1986]. It should be stressed that chromomeres are usually distributed irregularly along the axis, a feature that is more distinctive for avian LBCs. Regions of large chromomeres carrying a few small lateral loops alternate with regions of small chromomeres, which, on the contrary, carry many long loops (fig. 1a). Detailed schemes of LBCs reflecting the distribution of chromomeres, average loop length and positions of certain landmarks could be generated. Such maps have been produced for many urodele and anuran species and formed the very basis for the major accepted hypothesis on LBC structure. The developed cytological chromomere-loop maps of avian LBCs [Chelysheva et al., 1990; Rodionov and Chechik, 2002; Saifitdinova et al., 2003; Schmid et al., 2005; Galkina et al., 2006] facilitate determination of the pattern of gene transcription during oogenesis allowing assignment of the DNA fragments from the current genome sequence assemblies either to chromomere or to lateral loop. 

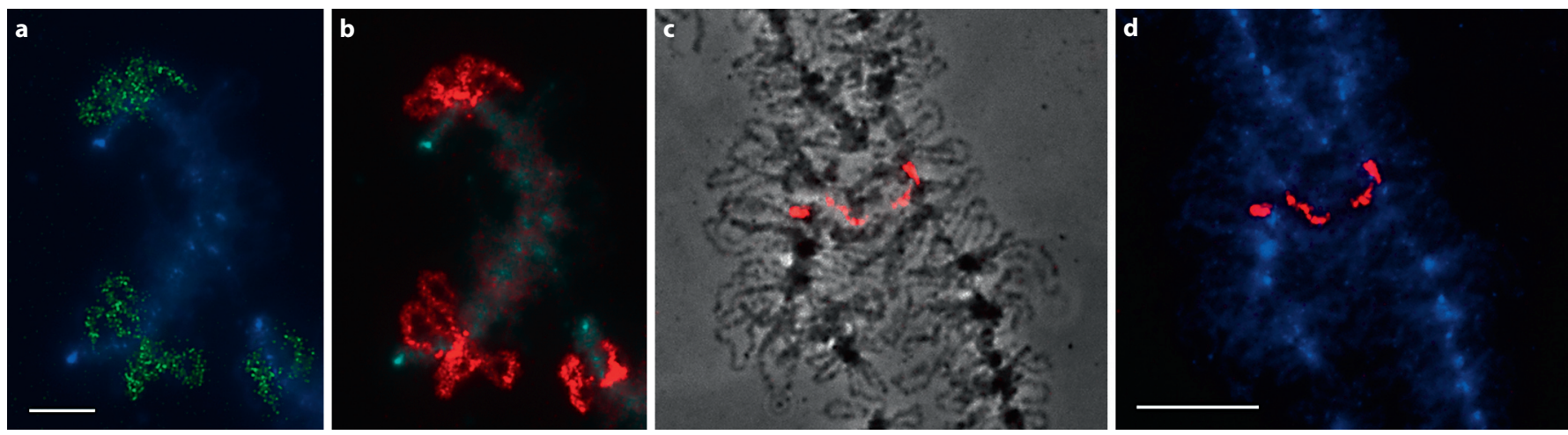

Fig. 3. Transcription of repetitive and unique sequences on avian lampbrush lateral loops. a FISH with oligonucleotide complimentary to PO41 tandem repeat (green) to quail lampbrush microbivalent demonstrates transcription of C-rich strand of the repeat on pericentromeric lateral loops. b RNP-matrix of pericentromeric lateral loops of the same microbivalent is enriched with

hnRNP protein K (red). c, d Fragment of the chicken lampbrush bivalent 1 . FISH with BAC clone bW069C11 according to DNA/ (DNA+RNA-transcript) hybridization protocol. In each half-bivalent RNP-matrix of two sister lateral loops is labeled (red). Scale bars $=10 \mu \mathrm{m}$.

The average length of LBCs in birds was shown to range from several $\mu \mathrm{m}$ for the smallest microbivalents up to $200 \mu \mathrm{m}$ for the longest bivalents and in general is smaller than in tailed amphibians [Kropotova and Gaginskaya, 1984; Chelysheva et al., 1990]. Identification of individual chicken, quail and chaffinch LBCs demonstrated that avian chromosomes in the lampbrush phase are at least 30 times longer than the corresponding metaphase chromosomes [Khutinaeva et al., 1989; Chelysheva et al., 1990; Rodionov and Chechik, 2002; Derjusheva et al., 2003; Saifitdinova et al., 2003; Galkina et al., 2005]. Consequently, fluorescence in situ hybridization (FISH) mapping on avian LBCs makes it possible to distinguish the order of closely positioned sequences and to reveal gene locations more precisely [Ogawa et al., 1997; Galkina et al., 2006].

The estimated average amount of DNA per chromomere (together with transcriptionally active loops) in chicken lampbrush macrochromosomes is about 1.5-2 $\mathrm{Mb}$ [Galkina et al., 2006]. In consequence, the resolution of comparative genome analysis using LBCs is close to the resolution of array-CGH on the platform of BAC-libraries. For example, the boundaries of chromosome rearrangements during karyotype evolution in Galliformes were revealed between certain chicken, quail and turkey macrochromosomes with very high cytogenetic resolution [Galkina et al., 2006; Griffin et al., 2008]. Moreover, the combination of physical gene mapping and immunodetection of kinetochore marker proteins made it possible to identify the centromeres on chicken and quail LBCs and to detail the positions of centromere regions in chromosome sequence assemblies for chicken macrochromosomes [Krasikova et al., 2006]. This integrative approach to genome analysis allowed revision of the positions of non-centromeric clusters of satellite repeat CNM and centromere in chicken chromosome 3.

As a rule, the diploid number of chromosomes in the avian karyotype is about 80 [Christidis, 1990]. It should be noted that numerous tiny microchromosomes, characteristic of avian karyotypes, are difficult to identify in metaphase preparations. Moreover, some of them still do not have any available sequence information. During oogenesis, avian microchromosomes assume the lampbrush form (fig. 3a), in which every microbivalent has one chiasma and a recognizable chromomere-loop pattern [Kropotova and Gaginskaya, 1984; Hutchison, 1987; Rodionov et al., 1992; Rodionov and Chechik, 2002]. Using chicken and quail microbivalents in the lampbrush form the distribution of 41-bp repeats was determined precisely [Krasikova et al., 2006; Deryusheva et al., 2007]. In contrast to chicken microchromosomes that are acrocentric, the majority of quail micros were found to be submetacentric; that fact was simultaneously demonstrated in the studies of Galliform lampbrush and synaptonemal complex karyotypes [Calderón and Pigozzi, 2006; Krasikova et al., 2006].

Another example of high-resolution mapping is detailed cytogenetic analysis of the chicken W chromosome constituted mainly of non-coding repeats. Evidence was provided indicating that distinct chromomeres of the 
chicken W LBC contain specific repetitive DNA sequence families, namely XhoI-, EcoRI and SspI-repeats [Ogawa et al., 1997; Solovei et al., 1998; Itoh and Mizuno, 2002], so that the sequences constituting only one of $7 \mathrm{~W}$ chromomeres, namely chromomere 7, are still unknown [Krasikova et al., 2006]. In general, $\mathrm{Z}$ and $\mathrm{W}$ sex chromosomes in the lampbrush form offer exclusive opportunities for solving some very interesting problems relating to the cytological and genomics aspects of sex determination; several informative reviews regarding this subject have been published [Mizuno and Macgregor, 1998; Schmid et al., 2005].

It should be noted that, being highly extended bivalents with distinctively recognized chiasmata (fig. 1a), avian LBCs are also widely used for positioning crossover events, estimation of crossover frequencies and construction of chiasma-based maps [Chelysheva et al., 1990; Rodionov et al., 1992a, b, 2002; Rodionov and Chechik, 2002; Galkina et al., 2005; Zakharova et al., 2006]. As a whole, the use of avian LBCs makes a great contribution to avian cytogenetics.

\section{Transcription of DNA Sequences on Avian Lampbrush Chromosomes}

As emphasized by Morgan [2002], one of the greatest benefits of the lampbrush system is opportunity for cytological analysis of gene expression. Indeed, due to their high transcriptional activity and easily detectable RNP matrix on transcriptional units, LBCs allow investigation of genome expression patterns and nascent RNA processing at the transcriptional level with remarkably high molecular resolution. DNA/RNA-transcript in situ hybridization is a reliable approach for revealing transcription even of unique sequences. In addition, microdissection of particular lampbrush parts followed by their cloning [Angelier et al., 1996; Saifitdinova et al., 2003] could give an opportunity to directly study transcribing sequences.

\section{Morphology of Transcription Units}

Despite the fact that the avian genome size is small, the majority of lateral loops in avian LBCs extend more than $15 \mu \mathrm{m}$ corresponding to at least $45 \mathrm{~kb}$ of DNA. Some giant loops may reach $80 \mu \mathrm{m}$ in length, however, these are quite rare [Kropotova and Gaginskaya, 1984; Gaginskaya, 1989; Khutinaeva et al., 1989; Chelysheva et al., 1990]. The size of transcription units in avian LBCs was shown to range from 1 to $40 \mu \mathrm{m}$. Each lateral loop usually con- tains one or several (up to 8) transcription units; the direction of transcription appears to be of functional significance. On simple lateral loops of chaffinch, pigeon and chicken LBCs transcription was demonstrated to be carried out by RNA polymerase II (fig. 1b) [Deryusheva et al., 2003; Saifitdinova et al., 2003; Krasikova et al., 2004].

Active ${ }^{3} \mathrm{H}$-uridine incorporation into the lateral loops of avian LBCs takes place at the middle diplotene, whereas at the late diplotene, the retraction of simple lateral loops is accompanied with a decrease in ${ }^{3} \mathrm{H}$-uridine incorporation [Callebaut, 1968; Gaginskaya and Gruzova, 1969; Gaginskaya, 1972b; Chin et al., 1979; Gaginskaya and Chin, 1980]. In the studies by Gaginskaya and Tsvetkov [1988] certain data were presented on the quantitative evaluation of RNA polymerase and nucleosome distribution in the chromatin of LBCs in dependence on the intensity of transcription. The density of RNA polymerases in transcription units on the LBC spreads from previtellogenic (1.25-1.8 $\mathrm{mm}$ in diameter) chicken oocytes was more than 20 complexes per $1 \mu \mathrm{m}$ of DNA fiber. In oocytes of 2-2.2 mm diameter, transcription units with 10 or even fewer RNA polymerases per micrometer are relatively numerous (fig. $2 \mathrm{~b}$ ).

\section{Transcription of Protein-Coding Genes and \\ Non-coding Unique Sequences}

The question of what nucleotide sequences do really transcribe on lampbrush loops is of great importance for understanding the significance of transcription during oogenesis. Strikingly, transcription of some housekeeping genes is repressed during the lampbrush stage. One of the examples is ribosomal RNA (rRNA) genes in hen GVs. In the chicken genome almost all clusters of $18 \mathrm{~S}$, $5.8 \mathrm{~S}$ and $28 \mathrm{~S}$ rRNA genes are located in microchromosome 16. In oocytes of sexually mature females these genes were found to be inactivated [Gaginskaya and Gruzova, 1969, 1975; Gaginskaya, 1972b, 1975]. The absence of functioning nucleoli in growing oocytes of adult avian females was first demonstrated by cytochemical reactions and analysis of ${ }^{3} \mathrm{H}$-uridine incorporation into the GV [Gaginskaya and Gruzova, 1969; Gaginskaya, 1972b]. Afterward, the absence of the nucleolus organizing activity in avian diplotene-stage oocytes was confirmed by in situ DNA/RNA hybridization [Gaginskaya and Gruzova, 1975]. The lack of nucleoli in avian oocytes is believed to be compensated by the transfer of rRNA from the follicular cells to the ooplasm by the so-called 'transosomes'. It is interesting to note that interspersed ribosomal DNA sequences can be transcribed on the lampbrush loops yet not by RNA polymerase I, the situation that was discov- 
ered for the European crested newt [Morgan et al., 1980]. Therefore non-specific, incidental transcription of rRNA genes on avian LBCs by RNA polymerase II cannot be ruled out.

There are only a few examples of unique gene transcription on both avian and amphibian LBCs. On lateral loops of amphibian LBCs only genes for cytokeratin, nucleolar protein NO38/B23 [Weber et al., 1989], c-myc and $\mathrm{Eg}_{1}$ [Angelier et al., 1996] were proven to be transcribed. At the same time, poly $(\mathrm{A})^{+}$RNA of the same complexity as in transcriptomes of somatic cells was shown to pass from the nucleus to ooplasm in Xenopus oocytes at the lampbrush stage [Davidson, 1986].

Unique modification of the conventional chromosome painting technique according to DNA/RNA hybridization protocol allows identification not only of certain chromosomes in the lampbrush form but also widespread transcription along the whole length of individual lampbrushes [Derjusheva et al., 2003]. Indeed, a lot of single copy genomic sequences were found to be actively transcribed on the lateral loops of avian LBCs (fig. 3c). Certain evidence in support of this was obtained in the study by Galkina et al. [2006], in which bacterial and P1derived artificial chromosomes (BAC and PAC) containing chicken genomic fragments were applied to chicken lampbrush macrobivalents. Among 39 BAC and PAC clones that bear unique microsatellite markers, 34 were mapped by FISH to the lateral loops, while only 5 were mapped to the chromomeres. It is worth noting that 12 BAC clones, which hybridize to the lateral loops of chicken LBC4, also hybridize to the lateral loops of Japanese quail LBC4 [Galkina et al., 2006], demonstrating that the pattern of transcription during oocyte growth is similar in 2 closely related species. It should be borne in mind that BAC inserts comprise both protein coding and noncoding DNA fragments. At the same time, no proteincoding sequences have been proven to be transcribed on the chicken gene-rich microchromosomes as yet. This raises the possibility that transcription of diverse protein coding genes on the LBCs is not obligate but rather incidental.

\section{Transcription of Satellite DNA}

It was supposed that the majority of DNA transcribed on the lampbrush loops is non-coding. Indeed, the transcription of tandemly repeated non-coding DNA in lampbrush stage oocytes was demonstrated for the first time by biochemical approaches [Davidson and Hough, 1971]. In further investigations, transcripts of satellite DNA were found on the lateral loops of amphibian LBCs using in situ hybridization technique [Macgregor and Andrews, 1977; Hartley and Callan, 1978; Varley et al., 1980a, b; Diaz et al., 1981; Macgregor et al., 1981; Jamrich et al., 1983; Baldwin and Macgregor, 1985; Barsacchi-Pilone et al., 1986; Epstein et al., 1986]. Such transcription is getting more intriguing in the view of modern data about the role of non-coding RNA in the regulation of eukaryotic genomes [Prasanth and Spector, 2007].

Some studies were directed to satellite DNA transcription on LBCs of various avian species. Avian LBCs usually carry terminal landmark loops (telomeric bow-like loops or TBLs), whereas it is rather an exception than a rule for amphibian LBCs [Chelysheva et al., 1990]. On chicken LBCs, the TBLs were shown to form at the chromosome termini carrying C-positive heterochromatic blocks [Rodionov et al., 1989] and to exhibit 2 transcription units - a short transcription unit corresponding to telomeric TTAGGG-repeat block and a long one situated before that and often running in the opposite direction [Solovei et al., 1994; Hori et al., 1996]. Earlier Hutchison [1987] had shown the terminal loops on chicken LBCs to be brightly labeled when hybridized in situ with total hen DNA. Later, the transcription of subtelomeric satellite DNA on terminal lateral loops was decisively demonstrated in chicken and quail LBCs. In fact, terminal heterochromatin of chicken chromosomes Z and 1-4 is composed of similar Z-macrosatellite repeats, which are transcribed by RNA polymerase II on TBLs of appropriate LBCs [Hori et al., 1996; our unpublished observations]. TBLs thus represent sites for the elaboration of $\mathrm{Z}$ macrosatellite non-coding RNA during the lampbrush period of oogenesis. Other examples of subtelomeric satellite DNA transcription involve 41-bp repeats from Galliform genomes [Krasikova et al., 2006; Deryusheva et al., 2007].

In avian oocytes of the lampbrush stage, massive transcription of pericentromere satellites has also been discovered. It was first demonstrated by Solovei et al. [1996], who showed the transcription of highly repetitive centromeric sequence PR1 on the lateral loops in the centromere regions of all LBCs in Columba palumbus (the wood-pigeon) [Solovei et al., 1996]. It seems exclusively important that in C. livia (the domestic pigeon), an almost identical repeat transcribes in none of the major pericentromeric sites. The authors suggested that the species-specific transcription is related to PR1 genome organization and can be explained on the basis of the 'readthrough' hypothesis.

When FISH with 41-bp non-coding repeats (CNM, PO41, BglII-repeat) from chicken and Japanese quail ge- 
nomes was performed on LBCs of these species, many clusters of transcribing units were observed in numerous lateral loops [Krasikova et al., 2006; Deryusheva et al., 2007] (fig. 3a). Ongoing transcription of these repeats has been verified by incorporation of BrUTP and by the presence of the elongating form of RNA polymerase II with the hyperphosphorylated C-terminal domain in the transcription units [Deryusheva et al., 2007]. It should be stressed that complementary transcripts of 41-bp repeats $\mathrm{CNM}$ and PO41 were revealed on long lateral loops of chicken LBCs. In the case of CNM, transcription of one strand occurs in one transcription unit, while transcription of another strand of the same repeat proceeds in a different chromosome locus. For example, in chicken microchromosomes, C-rich CNM transcripts were detected on loops extending from the pericentromere chromomeres, while G-rich transcripts of the same repeat were found on the q-terminal chromomeres [Krasikova et al., 2006]. At the same time, the presence of RNAs complementary to both strands of the repeat in the same transcription unit is a characteristic for PO41 indicating occurrence of short tracks of inverted repeats within the cluster [Deryusheva et al., 2007]. On the contrary, only G-rich transcripts of the CNM-like BglII-repeat are present in quail LBCs. It is worth noting that in Japanese quail LBCs, PO41 and BglII repeats are transcribed either in different transcription units, or continuously in the same transcription unit. Moreover, oppositely directed transcription of repeated DNAs was observed [Deryusheva et al., 2007]. The significance of such intensive non-coding DNA transcription in growing oocytes will be discussed in the following sections.

Recent data also demonstrate that the so-called male hypermethylated (MHM) region, located near the middle of the short arm of the chicken $\mathrm{Z}$ chromosome consists of tandem repeats and is transcribed only in females from the particular strand into heterogeneous in size, highmolecular-mass, non-coding RNA. In growing oocytes, transcripts from the MHM region were found on a pair of loops at the site of transcription, adjacent to the DMRT1 locus that lies at the base of these loops [Teranishi et al., 2001].

At the same time, it was shown by in situ hybridization that some $\mathrm{W}$-specific highly repetitive sequences were not transcribed in the chicken sex lampbrush bivalent. Likewise, transcription of 41-bp repeats on Galliform LBCs was found not to be obligatory and entire clusters of the repeats were non-transcribing [Krasikova et al., 2006; Deryusheva et al., 2007]. Moreover, if a satellite repeat is transcribed, the main part of the cluster of tandem copies remains silent and might be found in the adjacent chromomere. All this leads to the suggestion that specific regulatory sequences might be involved in the initiation of transcription of flanking satellite repeats.

\section{Regulation of Transcription on Lampbrush Lateral Loops}

The so-called 'read-through' hypothesis, at first suggested by Old et al. [1977] and later reinforced by Varley et al. [1980a, b] and Macgregor et al. [1981], was confirmed by Gall and his co-workers on the basis of in situ study of transcription at the histone gene loci on LBCs of Notophthalmus viridescens (the American newt) [Diaz et al., 1981; Gall et al., 1983]. The hypothesis postulates that on LBCs, transcription initiates at the structural gene promoters but does not terminate at the $3^{\prime}$ end of the gene, proceeding through downstream sequences including non-coding DNA. This hypothesis has played a role in understanding organization of transcription on LBCs and the existence of long transcription units on their lateral loops. However it does not explain all cases, in which structural genes were not found at the beginning of transcription units [Bromley and Gall, 1987], as well as the transcription of satellite DNA ongoing within the large block of heterochromatin where presence of structural genes seems unlikely.

A combination of genomic and cytological data allowed us to put forward another suggestion for the mechanisms that regulate satellite transcription in oocytes. Analysis of contigs containing 41-bp repeats from chicken genome databases reveals that long terminal repeats (LTR) of retrotransposons are present within satellite arrays and thus could provide their regulatory sequences for flanking tandem repeats [Deryusheva et al., 2007]. It does seem that LTR retrotransposons or even solo LTRs are responsible for the initiation of satellite transcription that is carried out by RNA polymerase II. Accordingly, RNA polymerase II transcribes LTR retrotransposons but not retrotransposons of the SINE family, which are known to be transcribed by RNA polymerase III.

Specific patterns of PR1 satellite transcription within centromere regions of pigeon LBCs [Solovei et al., 1996] and some other examples of satellite transcription in growing oocytes could be achieved by just the same mechanism. Indeed, both $\mathrm{Z}$ macrosatellites in chicken and PR1 satellites in pigeon reveal regular repeated association of transcription starting points with heterochromatic blocks. 
It seems reasonable that LBCs could sustain a simultaneous widespread transcription of RNA molecules from many thousands of promoters distributed along the lengths of all chromosomes. Interspersed repeats with their own functional promoters are also scattered throughout the genome. The important question is whether promoters of most of the RNA polymerase II transcription units on lampbrush lateral loops are represented by retroviral elements. If this is true, the average loop length should then inversely correlate with the density of active LTR promoters in the region.

Certain evidence in favor of this hypothesis was provided in early biochemical studies. As stressed by Macgregor [1984], the presence of two classes of poly(A) ${ }^{+}$ mRNAs in mature Xenopus oocytes was demonstrated in this work. One class is represented by maternal messenger RNAs, and the other class by incompletely processed very long transcripts consisting of a coding sequence and interspersed repeats [Thomas et al., 1981]. The nature of the latter transcripts could be explained by the initiation of transcription from the retrotransposon promoters, followed by transcription of single copy sequences including protein coding genes and spacer regions. Detailed exploration of the mechanisms of activation of interspersed repeats (namely retrotransposons) during the lampbrush stage is believed to be fruitful for understanding the nature of transcription units on LBCs.

\section{The Significance of Lampbrush Chromosomes in Oogenesis}

Since the start of investigations of LBCs, attempts have been made to understand and explain the 'widespread but somewhat indiscriminate transcription on lampbrush loops of a range of DNA sequences' [Macgregor, 1984]. However no satisfactory explanation for this transcription has yet been forthcoming. It has been suggested many times that read-through transcription of repetitive DNA on the lampbrush loops is 'more or less useless' and 'non-productive' [Macgregor, 1980, 1984; Angelier et al., 1996]. We offer here a novel interpretation of the 'classical' hypothesis, which states that LBCs provide transcripts, which are required for the early stages of embryogenesis and considers oocytes as an environment for the future embryo [Davidson, 1986].

It is likely that diverse maternal poly $(\mathrm{A})^{+} \mathrm{RNA}$ molecules transcribed during the lampbrush stage are sequestered until the dissolution of the nuclear membrane and then might undergo specific post-transcriptional cleav- age resulting in the formation of the 2 classes of RNA: protein-coding and non-coding sequences. Such an example of processing of the read-through transcripts of histone genes into mature transcripts dependent on factors present within the GV has been described in recent work of Masi and Johnson [2003]. We can then speculate that protein coding templates released after final processing can be utilized for protein synthesis in early embryos until activation of zygotic genome expression.

The fate of non-coding transcripts synthesized in the growing oocyte can be revised in the view of modern data. Indeed, it is now accepted that transcription of both strands of satellite DNA in metazoan chromosomes results in the production of long double-stranded (ds) precursor RNAs, which are subsequently processed into small interfering RNAs (siRNAs) [Matzke and Birchler, 2005; Prasanth and Spector, 2007]. Non-coding siRNA is known to be required for the formation of constitutive heterochromatin in particular at the pericentromeric regions of chromosomes [Almedia and Allshire, 2005; Kim, 2005]. We can hypothesize that the non-coding RNA product of satellite repeat transcription on the LBC lateral loops can hybridize to form long dsRNA molecules. These duplex-forming RNAs seem to be sequestered within the oocyte for the early stages of embryogenesis, where they probably provide a pool for the production of siRNAs used to establish the constitutive heterochromatin [Krasikova et al., 2006]. We can thus envisage that RNA-induced transcriptional silencing is inactivated in growing avian oocytes leading to the absence of inhibition of satellite RNA transcription on LBCs. Also it was suggested that unprocessed centromere-encoded RNAs from lampbrush loops could be used directly for centromere assembly [Deryusheva et al., 2007]. Studies are now in progress to determine whether synthesized satellite RNA is retained until fertilization. Taking into account these considerations the phenomenon of LBCs becomes clearer.

\section{Co-transcriptional RNA Processing on Lampbrush Lateral Loops}

While the nascent RNA chain is being synthesized by RNA polymerase II it attracts multifunctional complexes, which are usually involved in RNA processing and largely determine the fate of the mature RNA [Zhao, 1999; Aguilera, 2005]. RNP matrix of lampbrush lateral loops comprised of nascent, chromatin-associated transcripts apparently represents the most vivid model for 
studying co-transcriptional processes [Dreyfuss et al., 1993]. Indeed, use of the system has played a key role in establishing the co-transcriptional nature of RNA processing events and studying their mechanisms in vivo [Morgan, 2002, 2007; Sallacz and Jantsch, 2005; Patel et al., 2007].

Polarized RNP matrix of the majority of simple lateral loops of avian LBCs is shown to contain such spliceosome components as small nuclear (sn) RNPs and SC35 [Derjusheva et al., 2003; Krasikova et al., 2004] as well as some 3 ' end processing factors (unpublished data) and heterogeneous nuclear (hn) RNP proteins [Solovei et al., 1995; Deryusheva et al., 2007]. At the same time, there are some lateral loops, whose RNP matrixes possess an atypical protein composition (fig. 3b). Initially it was found that a range of chicken lampbrush loops binds single stranded C-nucleotide homopolymers [Solovei et al., 1995]. Since certain hnRNP proteins have preferential affinity to homonucleotide-rich RNA [Dreyfuss et al., 1993], it was suggested and then proved that binding of C-oligonucleotides with these loops is defined by enrichment of their RNP matrix with hnRNP protein K [Solovei et al., 1995]. This particular hnRNP protein is known to have high affinity to C-rich RNA [Matunis et al., 1993]. In the following studies, it was demonstrated that such atypical protein composition of RNP matrix is a result of specific RNA synthesis.

After the 41-bp satellite repeats were mapped on chicken LBCs it turned out that the distribution of lateral loops, containing C-rich transcripts of CNM and PO41 repeats, is very similar to the distribution of those described by Solovei et al. [1995] as enriched with hnRNP protein K. FISH, performed after immunodetection of hnRNP protein $\mathrm{K}$, fully confirmed that this protein is accumulated in the loops where C-rich transcripts of 41-bp repeats are being synthesized [Deryusheva et al., 2007]. Furthermore, in quail LBCs, C-rich transcripts of PO41 repeat were also found to co-localize with hnRNP K (fig. 3a, b). Non-uniform distribution of protein $\mathrm{K}$ within the RNP matrix of a single transcription unit bearing both C- and G-rich transcripts in quail LBCs clearly demonstrates the resolution provided by the LBC system [Deryusheva et al., 2007]. Using this approach, RNA sequence content of those loops that have atypical protein composition can be studied in detail.

Accurate investigation of the components of processing machinery within the RNP matrix of the loops transcribing 41-bp repeats in chicken and quail LBCs revealed that these loops do not contain any splicing snRNPs [Deryusheva et al., 2007]. Therefore it looks like the un- translatable transcripts of these pericentromeric and subtelomeric repeats do not undergo co-transcriptional snRNP dependent splicing. It was recently shown in a series of elegant experiments that even truncated, non-functional snRNAs target to nascent transcripts on lateral loops of amphibian LBCs [Patel et al., 2007]. This raises the possibility that the absence of snRNA in the RNP matrix of the satellite DNA bearing loops could just be due to the absence of canonical splicing sites within these non-coding transcripts.

Thus it can be concluded that non-coding, high-molecular-mass satellite RNA undergoes specific co-transcriptional packaging resulting in the formation of hnRNP complexes, of which the protein composition depends on the nucleotide content.

\section{Transcriptionally Inactive Structures Associated with Avian Lampbrush Chromosomes}

\section{Loop-like Domains of Complex Morphology}

There are special domains associated with LBCs which are not involved in on-going transcription. One type is loops with complex morphology [Callan, 1986; Morgan, 2002] or the so-called 'special loops' [Sallacz and Jantsch, 2005], which are enriched with RNA and seem to form at transcriptionally inactive loci. Recently, they were interpreted as a kind of intranuclear domain on amphibian LBCs [Sallacz and Jantsch, 2005]. The presence of 'special loops' is not an exclusive characteristic of amphibian LBCs - analogous structures form on LBCs of the majority of examined avian species. In chicken, pigeon and chaffinch GVs, 'special loops' are represented by the socalled 'terminal giant loops' (TGLs) and interstitial 'lumpy loops' (LLs) [Khutinaeva et al., 1989; Chelysheva et al, 1990; Solovei et al., 1994; Saifitdinova et al., 2003]. Although the size of 'special loops' can vary between individuals, they always form in specific chromosomal loci and serve as useful landmarks for individual LBCs for the majority of avian and amphibian lampbrush karyotypes.

Special loops have complex and variable morphology. The LLs usually have a compact globular form, whereas TGLs often exhibit looser and more extended conformation (fig. 4). TGLs also vary in prominence between species; for example, TGLs of pigeons are spectacularly long, reaching $100 \mu \mathrm{m}$ in length [Solovei et al., 1996]. Moreover, in wood pigeons nearly all TGLs are fused together forming gigantic star-like structures [Solovei et al., 1996]. The organization of TGLs merits special attention be- 

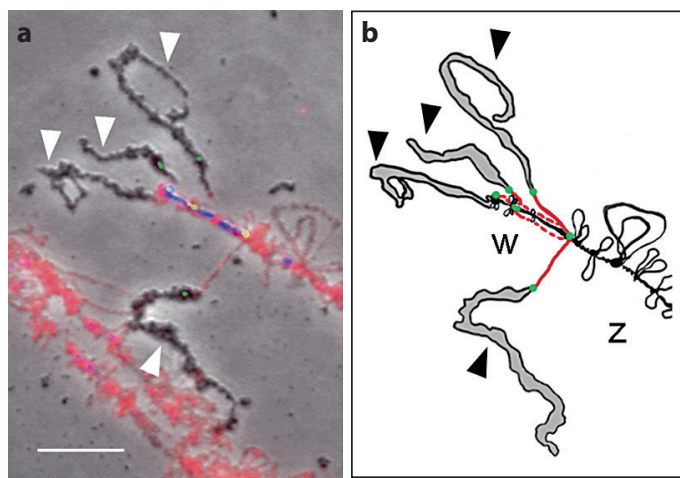
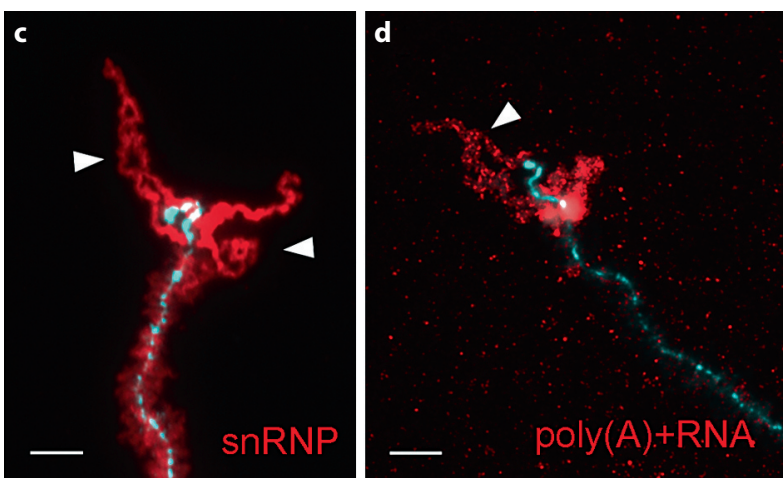

Fig. 4. Organization and composition of the so-called terminal giant loops (TGLs) associated with avian lampbrush chromosomes. Extended TGLs (arrowheads), which form at chiasmate ends of chicken chromosomes $\mathrm{W}$ and $\mathrm{Z}$, are presented. a Locations of TAAGGG repeat sites with regard to TGLs and transcriptionally active chromatin. FISH with (TAAGGG) 5 as a probe (green) after immunostaining with antibody against the elongating form of RNA polymerase II (red), chromosomes are counterstained with DAPI (blue). Fluorescent images are merged with the

cause of their terminal position on the chromosomes. FISH with a telomere TTAGGG probe to LBC with extended TGLs demonstrated that each chromatid ends at the base of a TGL structure (fig. 4a). In that case, a normal terminal lateral loop, which is located before the TGL, emerges from but does not return to the terminal chromomere according to the so called 'open ended' loop conformation (fig. 4b) [see also Solovei et al., 1994]. Thus, the TGLs appear not to be real lampbrush loops but massive aggregations of material accumulated on termini of certain LBCs.

TGLs and LLs have a specific molecular composition: they lack RNA polymerase II [Saifitdinova et al., 2003] but contain splicing factors (snRNPs and SC35) and a set of hnRNP proteins distinct from that in the RNP matrix of simple lateral loops (fig. 4c). 3D analysis of intact GVs demonstrates TGLs and LLs to be enriched with RNA in comparison to the nucleoplasm. It seems significant that these structures contain a bulk of poly (A) ${ }^{+}$RNA (fig. 4d), that is polyadenylated transcripts which had been already released from RNA polymerase II complexes and had undergone $3^{\prime}$ end processing (our unpublished data). Hence, the 'special loops' can be a kind of nuclear domain, in which hnRNA-hnRNP-snRNP complexes are accumulated and specifically retained during oocyte growth. phase contrast image. $\mathbf{b}$ Schematic drawing of the image shown on panel a illustrates that terminal telomere sites (green) are located at the base of TGL material on each of four chromatids. c Immunostaining with antibodies against 'Sm-epitope' of splicing snRNP (red). TGLs are brightly stained. Chromosomes are counterstained with DAPI (blue). d FISH with oligo(dT) 30 (red) and DAPI staining (blue). Hybridization signal is seen in TGLs but not in the RNP matrix of normal lateral loops. Scale bars $=10$ $\mu \mathrm{m}$.

\section{Centromere Protein Bodies}

Another type of transcriptionally inactive and conspicuous structure associated with avian lampbrush bivalents is the so called 'protein body' (PB) that has a perfect spherical shape (fig. 1a) [Gaginskaya and Gruzova, 1969; Gaginskaya, 1972b]. These remarkable nuclear bodies appear right at the beginning of the lampbrush stage within GVs of growing oocytes in all birds studied so far which represent at least 5 avian orders (Galliformes, Anseriformes, Columbiformes, Strigiformes, Passeriformes). They have a fibrillar fine structure with multiple vacuoles inside and spherules on their surface. Recent findings show that, as the 'special loops' described above, the PBs also lack RNA polymerase II. At the same time, no spliceosome components such as snRNPs and SR-proteins can be detected within avian PBs (fig. 5a) [Krasikova et al., 2004]. According to our unpublished observations of intact GVs, PBs do not contain any RNA and are exclusively composed of protein. A conclusion that $\mathrm{PBs}$ do not correspond to spheres or Cajal bodies characteristic of GVs of a wide variety of amphibian species [Callan and Lloyd, 1960; Gall and Callan, 1989; Gall, 2003] has been made [Krasikova et al., 2004].

Quite the opposite, PBs are the only type of nuclear bodies examined so far that were found to concentrate DNA topoisomerase II and cohesin complex proteins including members of the structural chromosome main- 

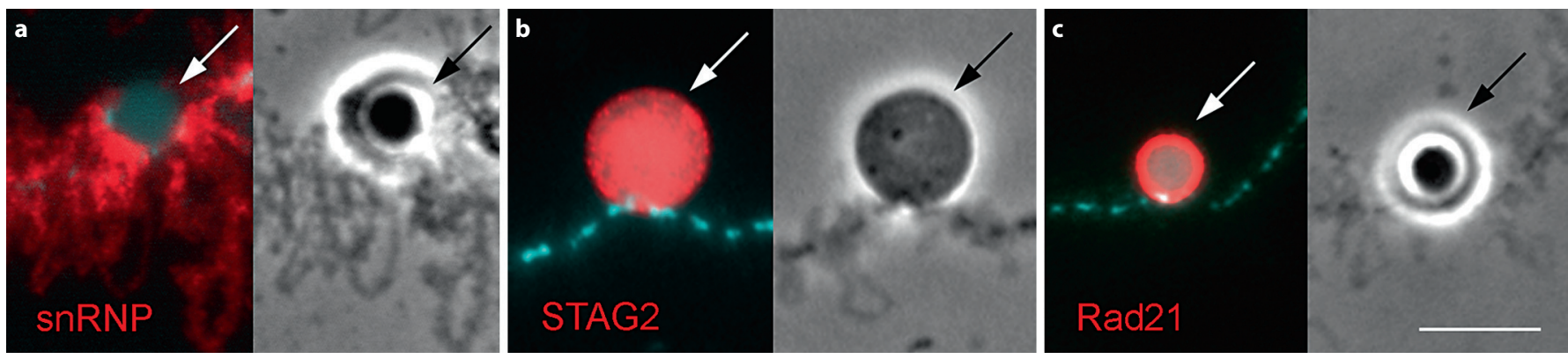

Fig. 5. Molecular composition of protein bodies (PBs) associated with centromere regions of avian lampbrush chromosomes. Immunostaining with antibodies against 'Sm-epitope' of splicing snRNP (a), cohesin components STAG2 (b) and Rad21 (c) (red). Chromosomes are counterstained with DAPI (blue). Corresponding phase contrast images are shown. Centromere PBs (arrows) contain proteins of the chromosome structural maintenance group and have a non-RNP nature. Scale bar $=10 \mu \mathrm{m}$.

tenance (SMC) group (fig. 5b, c) [Krasikova et al., 2004, 2005]. In addition, PBs are enriched with SYCP3, a protein that is known to participate in the formation of the lateral elements of synaptonemal complexes at the earlier stages of the first meiotic prophase [Krasikova et al., 2005]. The unique molecular composition of PBs in avian GVs has allowed us to consider them as a novel type of intranuclear bodies.

The very important point is that PBs form preferentially in association with centromere regions of chromosomes and are flanked by compact chromomeres comprising satellite DNA, such as the PR1 satellite in pigeons [Solovei et al., 1996], FCP satellite in chaffinch [Saifitdinova et al., 2003] and 41-bp repeats in chicken and quail LBCs [Krasikova et al., 2006]. Interestingly, morphologically similar 'centromere granules' can be found on the lampbrush bivalents of some tailed amphibians [Callan, 1986; Gall, 1992]. Although PBs could be classified as a kind of 'centromere locus body', the mechanism of their attachment to meiotic bivalents remains uncertain. The size of centromere PBs is known to vary in different species from $1 \mu \mathrm{m}$ in Galliformes to $20 \mu \mathrm{m}$ in Passeriformes. Being a universal GV structure, PBs serve as useful markers of lampbrush centromeres allowing cytological centromere mapping with unprecedented resolution [Krasikova et al., 2006]. It seems that PB formation reflects a special organization of chromosomal centromere regions at the lampbrush stage. Indeed, meiotic reductional division is characterized by monopolar orientation of sister kinetochores, while SYCP3 protein and certain cohesin subunits are known to be components of a molecular clip which holds sister kinetochores in meiotic bivalents [Parra et al., 2004].

Avian Lampbrush Chromosomes
The characteristic feature of $\mathrm{PBs}$ during oogenesis is their involvement in 3-dimensional genome organization during the period of karyosphere formation (postlampbrush stage) [Gaginskaya, 1972b]. Prior to nuclear envelope breakdown, centromere $\mathrm{PBs}$ associated with condensing bivalents fuse to form a karyosphere protein core [Saifitdinova et al., 2003; Krasikova et al., 2004]. As a result, centromere regions of all chromosomes are anchored in the surface of one large PB. Apparently, the concentration of the bivalents in the limited area of the enormous GV facilitates correct segregation of parental chromosomes [Gruzova and Parfenov, 1993; Rutkowska and Badyaev, 2008]. Taking into account the storage function of many oocyte organelles it seems important to follow the fate of the PB components after fertilization and in early embryo development.

\section{The 'Spaghetti Marker'}

In addition to centromere PBs and 'special loops' described above, there are some other enigmatic structures associated with avian LBCs. One example is an unusual landmark structure that forms on the short arm of the chicken lampbrush bivalent 2 and never assumes the appearance of a normal loop [Chelysheva et al., 1990]. The structure itself has a size between 2 and $5 \mu \mathrm{m}$ across. High resolution scanning electron microscopy used for examining this landmark revealed its unusual morphology: it looked like a bundle of spaghetti-like fibers, which had a width of either 15 or $35 \mathrm{~nm}$ [Solovei et al., 1992]. The structure is almost unlike anything previously seen on LBCs of any organism and due to its peculiar fine structure was called the 'spaghetti marker'. The spaghetti marker is resistant to RNase treatment and is largely

Cytogenet Genome Res 2009;124:251-267 
proteinaceous in nature [Solovei et al., 1992]. It was shown to contain specific but unidentified proteins that preferentially bind C-rich homonucleotides [Solovei et al., 1995]. However, the nature and function of 'spaghetti markers' are still unknown.

\section{Conclusion}

In this review, we have summarized and discussed the accumulated data on avian LBCs that have been a focus of research in the past 20 years. The advantages of the avian model include the small genome size, the existence of whole-chromosome painting probes and libraries of BACs and PACs containing genomic DNA fragments, and for the most part, the progress in deciphering the genomes of several species of birds. As a whole, avian LBCs give us a promising tool for integration of genome organization studies with analysis of genome expression and its regulation at the co-transcriptional level. In particular, there is a unique possibility for visualizing satellite RNA synthesis and processing at the cytological level on extended lateral loops. In addition, high-resolution cytogenetic analysis using giant LBCs makes a great contribution to comparative genomic research of domestic birds. Study of avian LBCs has also broadened the opportunities for exploration into general principles of meiotic chromosome organization and functioning.

At the same time it seems appropriate and promising to exploit avian LBCs for the investigation of chromosome-associated nuclear domains such as the spaghetti marker, transcriptionally inactive 'special loops' and normal loops accumulating specific RNPs through precise analysis of the loci of their formation. Future work should include investigations of LBCs in a third dimension within a morphologically preserved oocyte nucleus using confocal laser scanning microscopy. Due to the lack of both extra-chromosomal and chromosomal nucleoli, avian GVs offer unique opportunities to study LBC architecture and nuclear bodies of non-nucleolar nature. To date, the so-called protein bodies associated with centromere regions of avian LBCs were demonstrated to be nuclear bodies of a novel type, which concentrate DNAtopoisomerase II and proteins of the SMC group.

Nevertheless, there are a lot of unanswered questions and unsolved problems in avian lampbrushology. It seems challenging to determine the fate and functions of noncoding, high-molecular mass transcripts accumulating during the lampbrush phase of oogenesis. Our current hypothesis explaining the significance of widespread transcription during oocyte growth is based on both earlier concepts of the LBC phenomenon and the modern view of a role of RNA interference machinery in regulation of genome expression. We also suggest that initiation of transcription of non-coding genomic fragments depends on activation of LTR elements scattered along the whole length of LBCs. Future directions are believed to include the application of LBC study results to various fields of modern cell and developmental biology and establishing the meaning of the lampbrush phenomenon itself.

\section{Acknowledgements}

We express our thanks and gratitude to Herbert Macgregor for critical reading and careful editing of the manuscript. The authors would like to thank Svetlana Deryusheva for the images of fig. $3 \mathrm{a}$ and $4 \mathrm{c}$ and Anna Zlotina for the images of fig. $3 \mathrm{c}$, d. This investigation is supported by the Russian Foundation for Basic Research (grant No. 08-04-01328), State contract (No. 02.552.11.7044) and Saint-Petersburg government (grant No. 30-04/71). Some experimental data reviewed were obtained using Leica TCS SP5 microscope at the Core Facility 'CHROMAS' (Saint-Petersburg State University).

\section{References}

Aguilera A: Cotranscriptional mRNP assembly: Baldwin L, Macgregor HC: Centromeric satellite from the DNA to the nuclear pore. Curr Opin Cell Biol 17:242-50 (2005).

-Almedia R, Allshire RC: RNA silencing and genome regulation. Trends Cell Biol 5:251-258 (2005).

-Angelier N, Penrad-Mobayed M, Billoud B, Bonnafant-Ja' is M-L, Coumailleau P: What role might lampbrush chromosomes play in maternal gene expression? Int Dev BioI 40:645652 (1996).
DNA in the newt Triturus cristatus karelinii and related species: its distribution and transcription on lampbrush chromosomes. Chromosoma 92:100-107 (1985).

- Barsacchi-Pilone G, Batistoni R, Andronico F, Vitelli L, Nardi I: Heterochromatic DNA in Triturus (Amphibia, Urodela). I. A satellite DNA component of the pericentric C-bands. Chromosoma 93:435-446 (1986).
Beenders B, Watrin E, Legagneux V, Kireev I, Bellini M: Distribution of XCAP-E and XCAP-D2 in the Xenopus oocyte nucleus. Chromosome Res 11:549-564 (2003).

Brambell FWR: The oogenesis of the fowl (Gallus bankiva). Phil Trans R Soc London Ser B 214:113-151 (1926).

Bromley SE, Gall JG: Transcription of the histone loci on lampbrush chromosomes of the newt Notophthalmus viridescens. Chromosoma 95:396-402 (1987). 
Calderón PL, Pigozzi MI: MLH1-focus mapping in birds shows equal recombination between sexes and diversity of crossover patterns. Chromosome Res 14:605-612 (2006).

Callan HG: Lampbrush Chromosomes (Springer-Verlag, London 1986).

Callan HG, Lloyd L: Lampbrush chromosomes of crested newts Triturus cristatus (Laurenti). Phil Trans R Soc London Ser B 243:135219 (1960).

Callebaut M: [3H] Uridine incorporation during previtellogenesis and early vitellogenesis in the oocytes of the chick (Gallus gallus). J Embryol Exp Morphol 20:169-174 (1968).

Chelysheva LA, Solovei IV, Rodionov AV, Yakovlev AF, Gaginskaya ER: The lampbrush chromosomes of the chicken. The cytological map of macrobivalents. Tsitologiia 32: 303-316 (1990)

Chin SH, Gaginskaya ER, Kalinina EI: Peculiarities of oogenesis in the chicken. I. Extrafollicular period in the development of oocytes. Ontogenes (Russ) 10:340-349 (1979).

Christidis L: Animal Cytogenetics 4: Chordata 3 B: Aves (Gebrüder Borntraeger, Berlin 1990).

Davidson EH: Gene Activity in Early Development. Third edition (Academic Press, London 1986).

Davidson EH, Hough BR: Genetic information on oocyte RNA. J Mol Biol 56:491-506 (1971).

Derjusheva S, Kurganova A, Krasikova A, Saifitdinova A, Habermann FA, Gaginskaya E: Precise identification of chicken chromosomes in the lampbrush form using chromosome painting probes. Chromosome Res 11: 749-757 (2003)

-Deryusheva S, Krasikova A, Kulikova T, Gaginskaya E: Tandem 41-bp repeats in chicken and Japanese quail genomes: FISH mapping and transcription on lampbrush chromosomes. Chromosoma 116:519-530 (2007).

-Diaz MO, Barsacchi-Pilone G, Mahon KA, Gall JG: Transcripts from both strands of a satellite DNA occur on lampbrush chromosome loops of the newt Notophthalmus. Cell 24: 649-659 (1981)

Dreyfuss G, Matunis MJ, Piñol-Roma S, Burd CG: hnRNP proteins and the biogenesis of mRNA. Annu Rev Biochem 62:289-321 (1993).

Duryee WR: Isolation of nuclei and non-mitotic chromosome pairs from frog eggs. Arch Exp Zellforsch 19:171-176 (1937).

Epstein LM, Mahon KA, Gall JG: Transcription of a satellite DNA in the newt. J Cell Biol 103: 1137-1144 (1986).

- Fischer D, Hock R, Scheer U: DNA topoisomerase II is not detectable on lampbrush chromosomes but enriched in the amplified nucleoli of Xenopus oocytes. Exp Cell Res 209: 255-260 (1993).

Gaginskaya ER: The nuclear structures in oocytes of adult birds. I. Chromosome behavior during the oocyte cytoplasm growth. Tsitologiia 14:426-432 (1972a).
Gaginskaya ER: The nuclear structures in oocytes of adult birds. II. Protein bodies and the karyosphere. Tsitologiia 14:568-577 (1972b).

Gaginskaya ER: The problem of classification of oogeneses. Ontogenes (Russ) 6:539-545 (1975).

Gaginskaya ER: The lampbrush chromosomes in the amphibian oocytes. Tsitologiia 31: 1267-1291 (1989).

Gaginskaya ER, Chin SH: Peculiarities of oogenesis in the chicken. II. Follicular period in oocyte development. Ontogenes (Russ) 11: 213-221 (1980).

Gaginskaya ER, Gruzova MN: Peculiarities of the oogenesis in chaffinch. Tsitologiia 11: 1241-1251 (1969).

Gaginskaya ER, Gruzova MN: Detection of the amplified rDNA in ovarial cells of some insects and birds by hybridization in situ. Tsitologiia 17:1132-1137 (1975).

Gaginskaya ER, Tsvetkov AG: Electron microscopy research on the chromatin structure of dispersed lampbrush chromosomes in the hen. Tsitologiia 30:142-150 (1988).

Galkina S, Lukina N, Zakharova K, Rodionov A: Interstitial $(\mathrm{TTAGGG})_{(\mathrm{n})}$ sequences are hot spots of recombination in the chicken lampbrush macrochromosomes 1-3. Chromosome Res 13:551-557 (2005).

Galkina S, Deryusheva S, Fillon V, Vignal A, Crooijmans R, et al: EFISH on avian lampbrush chromosomes produces higher resolution gene mapping. Genetica 128:241-251 (2006).

Gall JG: Lampbrush chromosomes from oocyte nuclei of the newt. J Morphol 94:283-352 (1954).

Gall JG: Techniques for the study of lampbrush chromosomes, in Prescott DM (ed): Methods in Cell Physiology, vol II, pp 37-60 (Academic Press, London 1966).

Gall JG: Organelle assembly and function in the amphibian germinal vesicle. Adv Dev Biol 1: 1-29 (1992).

Gall JG: The centennial of the Cajal body. Nat Rev Mol Cell Biol 4:975-980 (2003).

Gall JG, Callan HG: The sphere organelle contains small nuclear ribonucleoproteins. Proc Natl Acad Sci USA 86:6635-6639 (1989).

Gall JG, Diaz MO, Stephenson EC, Mahon KA: The transcription unit of lampbrush chromosomes, in Subtelny S, Kafatos F (eds): Gene Structure and Regulation in Development. Soc Dev Biol Symp 41:137-146 (1983).

Gall JG, Wu Z, Murphy C, Gao H: Structure in the amphibian germinal vesicle. Exp Cell Res 296:28-34 (2004).

Greenfield ML: The oocyte of the domestic chicken shortly after hatching, studied by electron microscopy. Embryol Exp Morph 15:297-316 (1966)

-Griffin DK, Robertson LB, Tempest HG, Vignal A, Fillon V, et al: Whole genome comparative studies between chicken and turkey and their implications for avian genome evolution. BMC Genomics 9:168-184 (2008)
Gruzova MN, Parfenov VN: Karyosphere in oogenesis and intranuclear morphogenesis. Int Rev Cytol 144:1-52 (1993).

Guraya SS: Correlative cytological and histochemical studies on the avian oogenesis. Z Mikrosk Anat Forsch 90:91-150 (1976).

Hagstrom KA, Meyer BJ: Condensin and cohesin: more than chromosome compactor and glue. Nat Rev Genet 4:520-534 (2003).

- Hartley SE, Callan HG: RNA transcription on the giant lateral loops of the lampbrush chromosomes of the American newt Notophthalmus viridescens. J Cell Sci 34:279-288 (1978).

Hock R, Moorman A, Fischer D, Scheer U: Absence of somatic histone $\mathrm{H} 1$ in oocytes and preblastula embryos of Xenopus laevis. Dev Biol 158:510-522 (1993).

Holl M: Über die Reifung der Eizelle des Huhnes. Sitzungsber Akad Wiss Wien 99:311-370 (1890).

Hori T, Susuki Y, Solovei I, Saitoh Y, Hutchison $\mathrm{N}$, et al: Characterization of DNA sequences constituting the terminal heterochromatin of the chicken $\mathrm{Z}$ chromosome. Chromosome Res 4:411-426 (1996).

Hutchison N: Lampbrush chromosomes of the chicken. J Cell Biol 105:1493-1500 (1987).

-ICGSC (International Chicken Genome Sequencing Consortium): Sequence and comparative analysis of the chicken genome provide unique perspectives on vertebrate evolution. Nature 432:695-716 (2004).

- Itoh Y, Mizuno S: Molecular and cytological characterization of SspI-family repetitive sequence on the chicken $\mathrm{W}$ chromosome. Chromosome Res 10:499-511 (2002).

-Jamrich M, Warrion R, Steele R, Gall JG: Transcription of repetitive sequences on Xenopus lampbrush chromosomes. Proc Natl Acad Sci USA 80:3364-3367 (1983)

-Khutinaeva MA, Kropotova EV, Gaginskaya ER: Morpho-functional organization of the lampbrush chromosomes in oocytes of the pigeon Columba livia. Tsitologiia 31:11851192 (1989).

Kim VN: Small RNAs: Classification, biogenesis, and function. Mol Cells 19:1-15 (2005).

Koecke HU, Müller M: Change of form and number of chromosomes in chicken and duck. Naturwissenschaften 52:483 (1965).

Koschelt E, Heider K: Lehrbuch der Vergleichenden Entwicklungsgeschichte der Wirbellosen Thiere. Allgemeiner Theil I.-IV. Capitel; Ei und Eibildung (Gustav Fischer, Jena 1902).

Krasikova A, Kulikova T, Saifitdinova A, Derjusheva S, Gaginskaya E: Centromeric protein bodies on avian lampbrush chromosomes contain a protein detectable with an antibody against DNA topoisomerase II. Chromosoma 113:316-323 (2004).

Krasikova A, Barbero JL, Gaginskaya E: Cohesion proteins are present in centromere protein bodies associated with avian lampbrush chromosomes. Chromosome Res 13:675685 (2005) 
Krasikova A, Deryusheva S, Galkina S, Kurganova A, et al: On the positions of centromeres in chicken lampbrush chromosomes. Chromosome Res 14:777-789 (2006).

Kropotova EV, Gaginskaya ER: Lampbrush chromosomes from the Japanese quail oocytes: light and electron microscopic study. Tsitologiia 26:1008-1015 (1984).

-Lintern-Moore S, Moore GP, Tyndale-Biscoe $\mathrm{CH}$, Poole WE: The growth of the oocyte and follicle in the ovaries of monotremes and marsupials. Anat Rec 185:325-332 (1976).

Loyez M: Recherches sur le développement ovarian des oeufs méroblastiques à vitellus nutritive abundant. Arch Anat Microsc Morphol Exper 8:69-397 (1906).

Lund E, Paine PL: Nonaqueous isolation of transcriptionally active nuclei from Xenopus oocytes. Methods Enzymol 181:36-43 (1990).

-Macgregor HC: Recent developments in the study of lampbrush chromosomes. Heredity 44:3-35 (1980).

Macgregor HC: Lampbrush chromosomes and gene utilization in meiotic prophase. Symp Soc Exp Biol 38:333-347 (1984).

-Macgregor HC: Lampbrush chromosomes. J Cell Sci 88:7-9 (1987).

Macgregor HC: Lampbrush chromosomes. Retrieved from http://www.exeter.ac.uk/projects/lampbrush/ (2002).

-Macgregor HC, Andrews C: The arrangement and transcription of 'middle repetitive' DNA sequences on lampbrush chromosomes of Triturus. Chromosoma 63:109-126 (1977).

Macgregor HC, Klosterman L: Observations on the cytology of Bipes (Amphisbaenia) with special reference to its lampbrush chromosomes. Chromosoma 72:67-87 (1979).

Macgregor HC, Varley J: Working with Animal Chromosomes, 2nd ed (John Wiley \& Sons, New York 1988).

Macgregor HC, Varley JM, Morgan GT: The transcription of satellite and ribosomal DNA sequences on lampbrush chromosomes of crested newts, in Schweiger H-G (ed): International Cell Biology, pp 33-46 (SpringerVerlag, Berlin 1981).

Macgregor HC, Solovei I, Mizuno S: Lampbrush chromosomes as system for high resolution studies of meiotic chromosome structure, in Abbondandolo A, Vig BK, Roi R (eds): Chromosome Segregation and Aneuploidy, pp 172-183 (European Commission Joint Research Centre Publication, 1997).

Marko JF: Micromechanical studies of mitotic chromosomes. Chromosome Res 16:469497 (2008).

Masi T, Johnson AD: Read-through histone transcripts containing $3^{\prime}$ adenylate tails are zygotically expressed in Xenopus embryos and undergo processing to mature transcripts when introduced into oocyte nuclei. Biochem Biophys Res Commun 304:612-618 (2003).

Matunis EL, Matunis MJ, Dreyfuss G: Association of individual hnRNP proteins and snRNPs with nascent transcripts. J Cell Biol 121:219-228 (1993).
Matzke MA, Birchler JA: RNAi-mediated pathways in the nucleus. Nat Rev Genet 6:24-35 (2005).

Mizuno S, Macgregor H: The ZW lampbrush chromosome of birds: a unique opportunity to look at the molecular cytogenetics of sex chromosomes. Cytogenet Cell Genet 80: 149-157 (1998).

Morgan GT: Lampbrush chromosomes and associated bodies: new insights into principles of nuclear structure and function. Chromosome Res 10:177-200 (2002).

Morgan GT: Localized co-transcriptional recruitment of the multifunctional RNA-binding protein CELF1 by lampbrush chromosome transcription units. Chromosome Res 15:985-1000 (2007).

-Morgan GT, Macgregor HC, Colman A: Multiple ribosomal gene sites revealed by in situ hybridization of Xenopus rDNA to Triturus lampbrush chromosomes. Chromosoma 80 : 309-330 (1980).

- Ogawa A, Solovei I, Hutchison N, Saitoh Y, Ikeda JE, et al: Molecular characterization and cytological mapping of a non-repetitive DNA sequence region from the $\mathrm{W}$ chromosome of chicken and its use as a universal probe for sexing carinatae birds. Chromosome Res 5: 93-101 (1997).

Old RW, Callan GH, Gross KW: Localization of histone gene transcripts in newt lampbrush chromosomes by in situ hybridization. J Cell Sci 27:57-79 (1977).

- Organ CL, Shedlock AM, Meade A, Pagel M, Edwards SV: Origin of avian genome size and structure in non-avian dinosaurs. Nature 446:180-184 (2007).

- Parra MT, Viera A, Gomez R, Page J, Benavente $\mathrm{R}$, et al: Involvement of the cohesin $\operatorname{Rad} 21$ and SCP3 in monopolar attachment of sister kinetochores during mouse meiosis I. J Cell Sci 117:1221-1234 (2004).

Patel SB, Novikova N, Bellini M: Splicing-independent recruitment of spliceosomal small nuclear RNPs to nascent RNA polymerase II transcripts. J Cell Biol 178:937-949 (2007).

- Patel S, Novikova N, Beenders B, Austin C, Bellini M: Live images of RNA polymerase II transcription units. Chromosome Res 16: 223-232 (2008).

- Prasanth KV, Spector D: Eukaryotic regulatory RNAs: an answer to the 'genome complexity' conundrum. Genes Dev 21:11-42 (2007).

- Prasanth KV, Prasanth SG, Xuan Z, Hearn S, Freier SM, et al: Regulating gene expression through RNA nuclear retention. Cell 123: 249-263 (2005).

Rodionov AV, Chechik MS: Cytogenetic map of the Japanese quail lampbrush chromosomes. Genetika (Russ) 38:1246-1251 (2002).

Rodionov AV, Chelysheva LA, Kropotova EV, Gaginskaya ER: Heterochromatin regions of the chromosomes of the hen and Japanese quail in mitosis and at the lampbrush stage. Tsitologiia 31:867-873 (1989).
Rodionov AV, Myakoshina YA, Chelysheva LA, Solovei IV, Gaginskaya ER: Chiasmata in the lampbrush chromosomes of Gallus gallus domesticus: The cytogenetic study of recombination frequency and linkage map lengths. Genetika (Russ) 28:53-63 (1992a).

- Rodionov AV, Chel'sheva LA, Soloveř IV, Miakoshina IuA: Chiasma distribution in the lampbrush chromosomes of the chicken Gallus gallus domesticus: hot spots of recombination and their possible role in proper dysjunction of homologous chromosomes at the first meiotic division. Genetika (Russ) 28: 151-160 (1992b).

Rodionov AV, Galkina SA, Lukina NA, Solovei I, Saccone S: Crossing over in chicken oogenesis: cytological and chiasma-based genetic maps of the chicken lampbrush chromosome 1. J Hered 93:125-129 (2002).

Rutkowska J, Badyaev AV: Meiotic drive and sex determination: molecular and cytological mechanisms of sex ratio adjustment in birds. Phil Trans R Soc Lond B Biol Sci 363:16751686 (2008).

Ryan J, Llinas AJ, White DA, Turner BM, Sommerville J: Maternal histone deacetylase is accumulated in the nuclei of Xenopus oocytes as protein complexes with potential enzyme activity. J Cell Sci 112:2441-2452 (1999).

- Saifitdinova A, Derjusheva S, Krasikova A, Gaginskaya E: Lampbrush chromosomes of the chaffinch (Fringilla coelebs L.). Chromosome Res 11:93-113 (2003).

Saitoh Y, Saitoh H, Ohtomo K, Mizuno S: Occupancy of the majority of DNA in the chicken W chromosome by bent-repetitive sequences. Chromosoma 101:32-40 (1991).

Sallacz NB, Jantsch MF: Chromosomal storage of the RNA-editing enzyme ADAR1 in Xenopus oocytes. Mol Biol Cell 16:3377-3386 (2005).

-Schmid M, Nanda I, Hoehn H, Schartl M, Haaf $\mathrm{T}$, et al: Second report on chicken genes and chromosomes. Cytogenet Genome Res 109: 415-479 (2005).

Smillie DA, Llinas AJ, Ryan JT, Kemp GD, Sommerville J: Nuclear import and activity of histone deacetylase in Xenopus oocytes is regulated by phosphorylation. J Cell Sci 117: 1857-1866 (2004).

- Solovei I, Gaginskaya E, Allen T, Macgregor H: A novel structure associated with a lampbrush chromosome in the chicken, Gallus domesticus. J Cell Sci 101:759-772 (1992).

-Solovei I, Gaginskaya E, Hutchison N, Macgregor H: Avian sex chromosomes in the lampbrush form: the ZW lampbrush bivalent from six species of bird. Chromosome Res 1:153-166 (1993).

Solovei I, Gaginskaya ER, Macgregor HC: The arrangement and transcription of telomere DNA sequences at the ends of lampbrush chromosomes of birds. Chromosome Res 2: 460-470 (1994). 
Solovei I, Macgregor H, Gaginskaya E: Single stranded nucleic acid binding structures on chicken lampbrush chromosomes. J Cell Sci 108:1391-1396 (1995).

-Solovei IV, Joffe BI, Gaginskaya ER, Macgregor HC: Transcription on lampbrush chromosomes of a centromerically localized highly repeated DNA in pigeon (Columba) relates to sequence arrangement. Chromosome Res 4: 588-603 (1996).

-Solovei I, Ogawa A, Naito M, Mizuno S, Macgregor $\mathrm{H}$ : Specific chromomeres on the chicken W lampbrush chromosome contain specific repetitive DNA sequence families. Chromosome Res 6:323-327 (1998).

Sommerville J, Baird J, Turner BM: Histone H4 acetylation and transcription in amphibian chromatin. J Cell Biol 120:277-290 (1993).

- Stewart MD, Sommerville J, Wong J: Dynamic regulation of histone modifications in Xenopus oocytes through histone exchange. Mol Cell Biol 26:6890-6901 (2006).
Teranishi M, Shimada Y, Hori T, Nakabayashi O, Kikuchi T, Macleod T, et al: Transcripts of the MHM region on the chicken $\mathrm{Z}$ chromosome accumulate as non-coding RNA in the nucleus of female cells adjacent to the DMRT1 locus. Chromosome Res 9:147-165 (2001).

Thomas TL, Posakony JW, Anderson DM, Britten RJ, Davidson EH: Molecular structure of maternal RNA. Chromosoma 84:319-335 (1981).

van Durme M: Nouvelles recherches sur la vitellogenèse des oeufs d'oiseaux studies d'accroissement, de fécundation et du début la germentation. Arch boil (Liège) 29:71-200 (1914).

Varley JM, Macgregor HC, Erba HP: Satellite DNA is transcribed on lampbrush chromosomes. Nature 283:686-688 (1980a).

Varley JM, Macgregor HC, Nardi I, Andrews C, Erba HP: Cytological evidence of transcription of highly repeated DNA sequences during the lampbrush stage in Triturus cristatus carnifex. Chromosoma 80:289-307 (1980b).
Weber T, Schmidt E, Scheer U: Mapping of transcription units on Xenopus laevis lampbrush chromosomes by in situ hybridization with biotin-labeled cDNA probes. Eur J Cell Biol 50:144-153 (1989).

Wylie CC: Nuclear morphology and nuclear DNA synthesis during meiotic prophase in oocytes of the chick (Gallus domesticus). Cell Diff 1:325-334 (1972).

Zakharova KV, Galkina SA, Lukina NA, Rodionov AV: Crossing over in the oogenesis of Gallus gallus domesticus chickens: periodicity in the distribution of chiasmata over the length of chromosomes. Genetika (Russ) 42: 844-849 (2006).

Zhao J, Hyman L, Moore C: Formation of mRNA $3^{\prime}$ ends in eukaryotes: mechanism, regulation, and interrelationships with other steps in mRNA synthesis. Microbiol Mol Biol Rev 63:405-445 (1999). 